\title{
Recent Research Progress in Solar Thermal Conversion Theory and Applications
}

\author{
Gang Pei, ${ }^{1}$ Yuehong Su, ${ }^{2}$ Sauro Filippeschi, ${ }^{3}$ and Hongfei Zheng ${ }^{4}$ \\ ${ }^{1}$ Department of Thermal Science and Energy Engineering, University of Science and Technology of China, Hefei, Anhui 230026, China \\ ${ }^{2}$ Department of Architecture and Built Environment, The University of Nottingham, Nottingham NG7 2RD, UK \\ ${ }^{3}$ Department of Energy, System, Territory and Constructions Engineering, University of Pisa, 55126 Pisa, Italy \\ ${ }^{4}$ School of Mechanical and Vehicle Engineering, Beijing Institute of Technology, Beijing 100081, China
}

Correspondence should be addressed to Gang Pei; peigang@ustc.edu.cn

Received 6 July 2015; Accepted 7 July 2015

Copyright (C) 2015 Gang Pei et al. This is an open access article distributed under the Creative Commons Attribution License, which permits unrestricted use, distribution, and reproduction in any medium, provided the original work is properly cited.

Thermal use is one of the most important ways in solar energy utilization. The global solar thermal industry is growing fast. More than 100 million square meters of solar collectors were produced worldwide in 2014. Typical applications of solar thermal technologies are water heating, space heating and cooling, refrigeration, industrial process heat, desalination, power generation, lighting, and so forth. Research and development in the scientific and technical fields of solar energy conversion are very active nowadays, and the room for improvement and innovation remains large.

Works published in this special issue are contributions to solar thermal conversion.

To improve heat collection efficiency of traditional allglass evacuated tube collectors (ETC), J. Yang et al. have proposed novel ETC with an inserted tube in "A Study on Thermal Performance of a Novel All-Glass Evacuated Tube Solar Collector Manifold Header with an Inserted Tube." Water inside the collector experiences forced convection rather than natural convection. Heat transfer between water and the inner glass tube is therefore increased. The novel collector offers an efficiency increment of 5\% compared with that without an inserted tube.

Comprehensive utilization of solar collector is an important topic. J. Ma et al. have investigated the dual-functional solar collector (DFSC) in "Performance Investigation and Structure Optimization of a Flat Dual-Function Solar Collector." The DFSC can supply hot water or hot air depending on the consumer's seasonal demands. A dynamic numerical model has been established to optimize the structure parameters. According to the model, the back insulation of DFSC needs to be as thick as $6 \mathrm{~cm}$ to prevent heat loss via backboard; the equal depth of $3-4 \mathrm{~cm}$ of the upper and lower channels is optimal for both air heating and water heating modes.

Solar collector can serve as not only heater but also radiative cooler. $\mathrm{M}$. Hu et al. have proposed spectrally selective surface for both solar heating and radiative cooling in "Theoretical and Experimental Study of Spectrally Selectivity Surface for Both Solar Heating and Radiative Cooling." The collector surface has a high spectral absorptivity in the solar radiation band and atmospheric window band (i.e., $0.2 \sim 3 \mu \mathrm{m}$ and $8 \sim 13 \mu \mathrm{m})$ and low absorptivity or emissivity in other bands (i.e., $3 \sim 8 \mu \mathrm{m}$ or above $13 \mu \mathrm{m}$ ). The collector works in solar heating mode during daytime and radiative cooling mode during nighttime. It has been shown that polyethylene terephthalate is an alternative selective surface coating for the proposed solar collector design, which can achieve relative heat collection efficiency of $76.8 \%$ in comparison to a conventional solar collector surface and a relative temperature difference of $75.0 \%$ compared with a conventional radiative cooling surface.

The overall efficiency of a solar collector gets higher when combined with PV cell. $\mathrm{H}$. Chen et al. have studied a heat pipe photovoltaic/thermal solar collector in "Numerical and Experimental Study on Energy Performance of PhotovoltaicHeat Pipe Solar Collector in Northern China." The collectors of this kind are applicable in cold regions without the problem of freezing. A simplified one-dimensional steady state model has been developed to study the electrical and thermal performance of the collector. A testing rig has been built to verify the model. 
Medium temperature solar collector is also attracting great interest. H. Zheng et al. have investigated a shell-encapsulated solar collector which can be used in north area of China for wall-mounted installation in "Design and Testing of a Shell-Encapsulated Solar Collector with the Compound Surface Concentrators." The collector is based on the combination of a novel compound curved surface concentrator and an aluminum concentric solar receiver, which is contained in a glass evacuated tube. It has daily average efficiency about $45 \sim 50 \%$ under the conditions of hot water temperature above $80^{\circ} \mathrm{C}$ and ambient temperature below $0^{\circ} \mathrm{C}$. A new trough solar concentrator which is composed of multiple reflective surfaces has also been developed in "Study on a Midtemperature Trough Solar Collector with Multisurface Concentration." A main CPC concentrator and a secondary parabolic reflector with two straight edges and a bottom are used as the reflectors. The collector offers convenience for installation and thermal insulation of the receiver and reduces the demand for solar tracking precision. Instantaneous efficiency more than $45 \%$ can be achieved at the operation temperature higher than $145^{\circ} \mathrm{C}$.

Solar thermal power generation has great potential to reduce the consumption of fossil fuel. $\mathrm{R}$. Zhai et al. have studied solar assisted coal-fired power generation system (SACFPGS) in "Improved Optimization Study of Integration Strategies in Solar Aided Coal-Fired Power Generation System." The SACFPGS has advantages over solar thermal power generation system regarding the elimination of steam turbine and generator. It also has less coal consumption than traditional coal-fired system. The genetic algorithm is used to optimize the solar collector field area and thermal storage capacity. It shows that the improvement of the thermal storage system effectively leads to more cost-effective SACFPGS.

Solar lighting is also capable of reducing energy consumption and environmental pollution. X. Qin et al. have estimated the energy saving and environmental impact of solar lighting technologies in "Solar Lighting Technologies for Highway Green Rest Areas in China: Energy Saving, Economic, and Environmental Evaluation." A case study on solar lighting for a highway rest area of $904 \mathrm{~m}^{2}$ is presented. It is shown that natural light guiding system can bring about energy saving of $29696.4 \mathrm{kWh}$ during day time. While using solar photovoltaic LED lamp, the energy saving is $219000 \mathrm{kWh}$. The total annual energy saving by the solar lighting technology including solar photovoltaic LED lighting and natural light guiding systems can reduce 99.5 tons of equivalent standard coal.

\section{Acknowledgments}

At the end, we would like to thank all the authors and reviewers for the contribution to this issue.

$$
\begin{array}{r}
\text { Gang Pei } \\
\text { Yuehong Su } \\
\text { Sauro Filippeschi } \\
\text { Hongfei Zheng }
\end{array}
$$



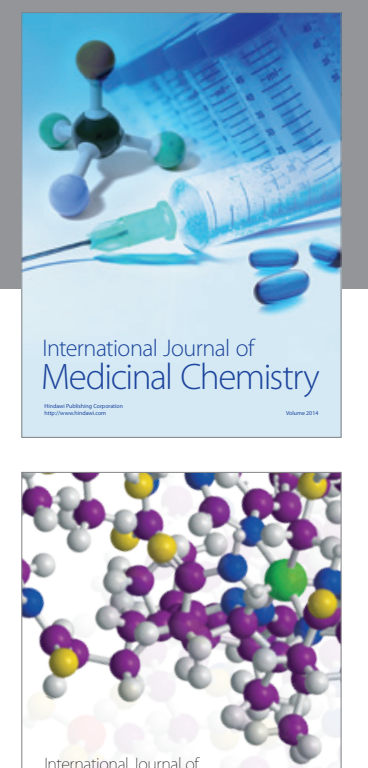

\section{Carbohydrate} Chemistry

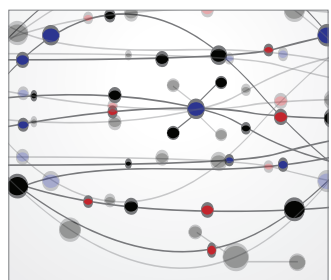

The Scientific World Journal
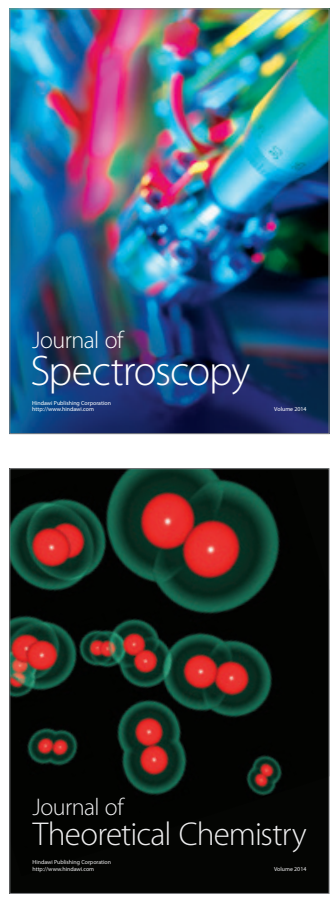
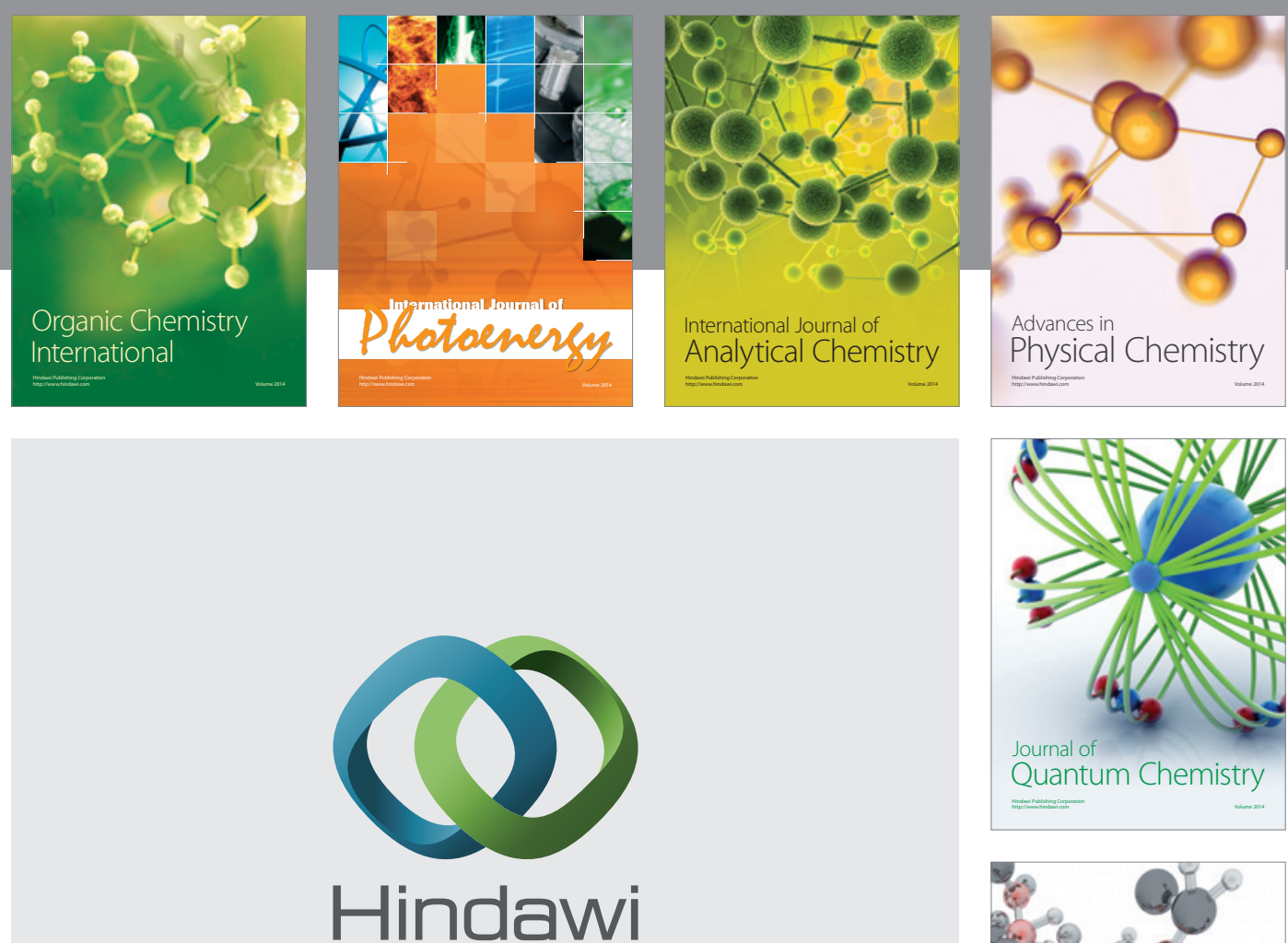

Submit your manuscripts at

http://www.hindawi.com

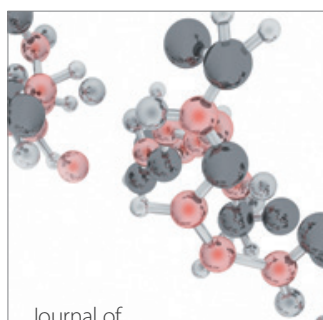

Analytical Methods

in Chemistry

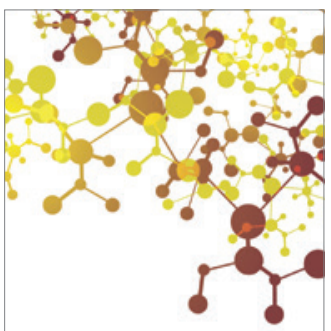

Journal of

Applied Chemistry

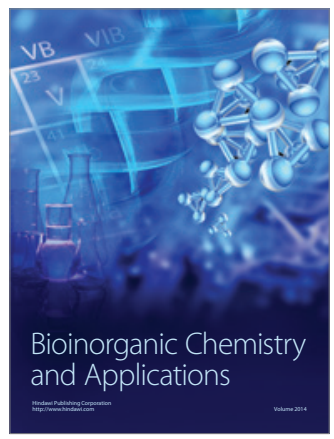

Inorganic Chemistry
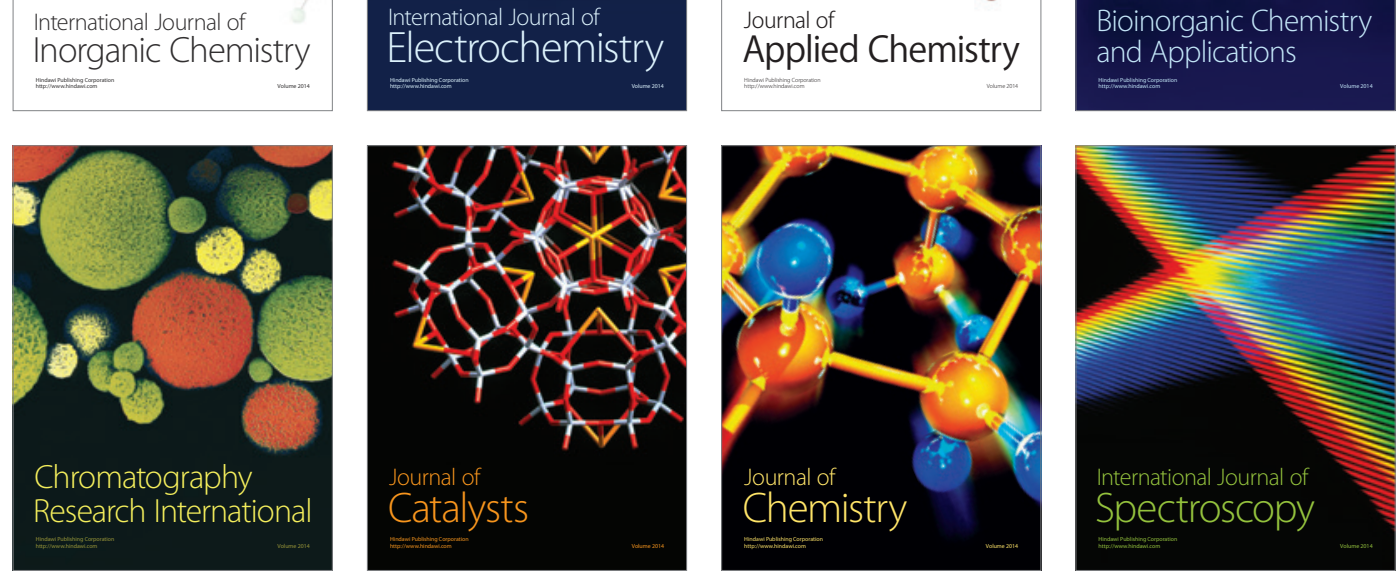